\title{
A checklist of macroparasites of Liza haematocheila (Temminck \& Schlegel) (Teleostei: Mugilidae)
} Aneta Kostadinova ${ }^{1,2}$

Address: ${ }^{1}$ Institute of Parasitology, Biology Centre of the Czech Academy of Sciences, Branišovská 31, 37005 \&\#x010C; eské Bud\&\#x011B;jovice,
Czech Republic and ${ }^{2}$ Central Laboratory of General Ecology, Bulgarian Academy of Sciences, 2 Gagarin Street, 1113 Sofia, Bulgaria

Email: Aneta Kostadinova - aneta.kostadinova@uv.es

Published: 31 December 2008

Parasites \& Vectors 2008, I:48 doi:10.1186/1756-3305-I-48
Received: 30 July 2008

Accepted: 31 December 2008

This article is available from: http://www.parasitesandvectors.com/content/l///48

(c) 2008 Kostadinova; licensee BioMed Central Ltd.

This is an Open Access article distributed under the terms of the Creative Commons Attribution License (http://creativecommons.org/licenses/by/2.0), which permits unrestricted use, distribution, and reproduction in any medium, provided the original work is properly cited.

\begin{abstract}
Background: The mugilid fish Liza haematocheila (syn. Mugil soiuy), native to the Western North Pacific, provides opportunities to examine the changes of its parasite fauna after its translocation to the Sea of Azov and subsequent establishment in the Black Sea. However, the information on macroparasites of this host in both ranges of its current distribution comes from isolated studies published in difficult-to-access literature sources.
\end{abstract}

Materials and methods: Data from 53 publications, predominantly in Chinese, Russian and Ukrainian, were compiled from an extensive search of the literature and the Host-Parasite Database maintained up to 2005 at the Natural History Museum, London.

Results: The complete checklist of the metazoan parasites of $L$. haematocheila throughout its distributional range comprises summarised information for 69 nominal species of helminth and ectoparasitic crustacean parasites, from 45 genera and 27 families (370 host-parasite records in total) and includes the name of the parasite species, the area/locality of the host capture, and the author and date of the published record. The taxonomy is updated and the validity of the records and synonymies are critically evaluated. A comparison of the parasite faunas based on the records in the native and introduced/invasive range of $L$. haematocheila suggests that a large number of parasite species was 'lost' in the new distributional range whereas an even greater number was 'gained'.

Conclusion: Although the present checklist provides information that will facilitate future studies, the interesting question of macroparasite faunal diversity in L. haematocheila in its natural and introduced/invasive ranges cannot be dealt with the current data because of unreliability associated with the large number of non-documented and questionable records. This stresses the importance of data quality analysis in using host-parasite database and checklist data.

\section{Background}

Liza haematocheila (Temminck \& Schlegel, 1845) (syn. Mugil soiuy Basilewsky, 1855 see e.g. [1-3]), native to the Western North Pacific, provides an intriguing case for studying the effect of host translocation on parasite fauna because of the disparity of its introduced and natural range and the presence of a number sympatric mullet species in the former. L. haematocheila established a successful breeding population in the Sea of Azov in the early 1980s after numerous deliberate introduction attempts to sup- 
port commercial fisheries [4] and is now the most abundant mugilid species present [5]. This species has already been established in the north-eastern Black Sea where it is a subject to commercial fisheries in Russia and the Ukraine since 1995. A small stock has been exploited along the Turkish coasts since the 1990s. The environmental conditions in the new species range appear to favour this species whose growth rate exceeds that of the native mullet species [6]; its expansion in the Black Sea coincides with a decline in the native mullet species which it apparently replaces [5]. Furthermore, L. haematocheila has been recorded in the Aegean Sea and Starushenko \& Kazanski [7] predicted its ongoing invasion towards the Western Mediterranean.

The idea that the translocation and introduction of hosts into areas outside their natural distributional range results in a reduction in the number of their parasite species or a loss of their original parasite fauna was first formulated in the classical works of Dogiel $[8,9]$. This generalisation was reinforced by Kennedy \& Bush [10] and has recently gained empirical support in tests of the 'enemy release' hypothesis at the host population level $[11,12]$. However, studies on teleost host-parasite systems are notably few in the marine environment (see Torchin et al. [11] for a review). An important prerequisite for such studies is the delineation of the parasite faunas in both fish native and invasive range; this incorporates the use of an updated taxonomy and quality assessment of the existing data.

This paper presents the first checklist of helminth and crustacean parasite species recorded in L. haematocheila in which largely scattered host-parasite records written in Chinese, Russian and Ukrainian and from difficult-toaccess literature sources are compiled in an attempt to provide a biogeographical framework for future research on the role of parasites in the possible outcomes of invasion of L. haematocheila in the Mediterranean. The taxonomy is updated and the validity of the records and synonymies are critically evaluated and discussed.

\section{Methods}

Data for the checklist were compiled from an extensive search of the literature and the Host-Parasite Database maintained at the Natural History Museum, London [13]. The main limitations of the data are related to the very small number of documented records (i.e. providing supportive evidence for the species identification $e$.g. description and/or figure/metrical data); these are indicated in the checklist (Additional file 1). Another feature of the data is that many records represent re-iterations of previous records (but without citations in a large number of cases especially in the Sea of Azov and Black Sea). The bias due to re-iteration of own records in a number of abstracts/species lists is obvious in the latter region where three teams have published on the parasite fauna of $L$. haematocheila, i.e. Dmitrieva and Gaevskaya [14-18], Maltsev and colleagues [19-26] and Sarabeev and Domnich [27-34]. The records of these teams alone come from 21 publications (out of 27 for the Sea of Azov and the Black Sea).

\section{Results}

Altogether 69 species of helminth and ectoparasitic crustacean parasites from 45 genera and 27 families have so far been reported in Liza haematocheila; of these, 8 are identified to generic level (Additional file 1). Digeneans represent the most diverse group of parasites in this host (36 species belonging to 25 genera and 10 families), whereas the other higher-level taxonomic groups are poorly represented (11 monogeneans, 9 nematodes, 6 copepods, 4 acanthocephalans, 2 cestodes, and 1 isopod).

The parasite fauna of L. haematocheila appears to be more intensively studied in the Sea of Azov and the Black Sea (a total of 281 host-parasite records) as compared to Western North Pacific (89 records). At first glance this more than three fold difference indicates that differential study effort might have biased the data on faunal richness in the two areas. However, a reverse difference of the same magnitude is observed when only documented records are considered (i.e. 12 vs 37 records, respectively, see Additional file 1). A total of 33 species (documented records for 24) were found to parasitize L. haematocheila in its natural (Western North Pacific) range and 44 species (documented records for 8 ) were recorded in its introduced/ invasive range (Sea of Azov/Black Sea). Of these nine were reported in both areas: the monogeneans Ligophorus chabaudi Euzet \& Suriano, 1977, Ligophorus kaohsianghsieni (Gusev, 1962), Ligophorus llewellyni Dmitrieva, Gerasev \& Pron'kina, 2007, Ligophorus pilengas Sarabeev \& Balbuena, 2004, Gyrodactylus mugili Zhukov, 1970, Gyrodactylus zhukovi Ling, 1962, Microcotyle mugilis Vogt, 1878 and the acanthocephalans Neoechinorhynchus agilis (Rudolphi, 1819) and Acanthogyrus (Acanthosentis) tylosuri (Yamaguti, 1939).

The higher-level taxonomic structure of the parasite fauna of $L$. haematocheila in the two distributional ranges is graphically represented in Figure 1 . The figure shows the relative representation in terms of number of species of the major parasite taxonomic groupings, namely, Monogenea, Digenea (adult and larval forms separately), Cestoda, Nematoda, Acanthocephala, Copepoda and Isopoda. The species representation is generally similar except for monogeneans which represent a higher proportion of all species in the natural range and digeneans which predominate in the introduced/invasive range of the host. Digeneans also exhibit a reverse pattern with respect to the ratio adult/larval forms, the latter compris- 


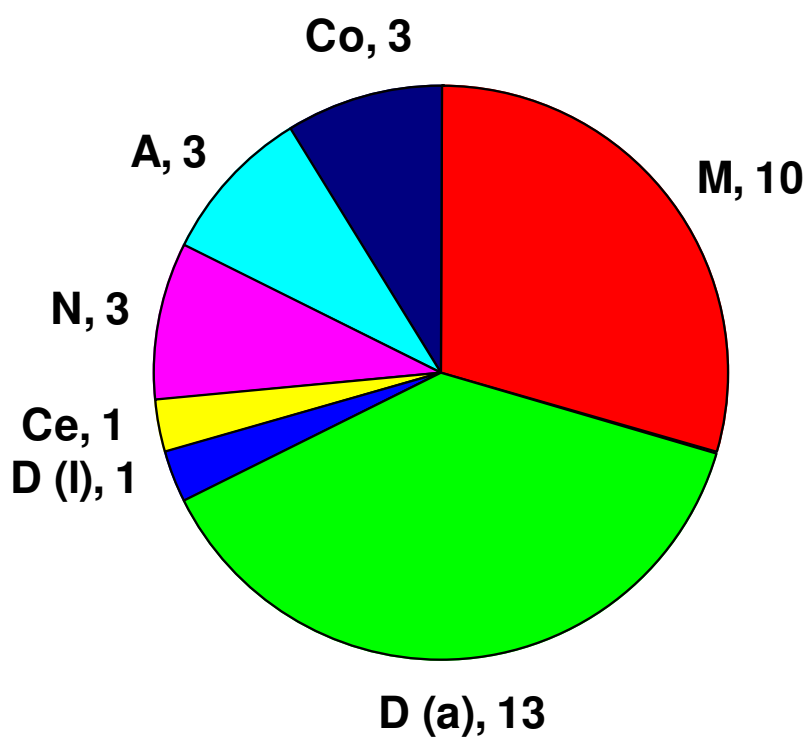

North-West Pacific

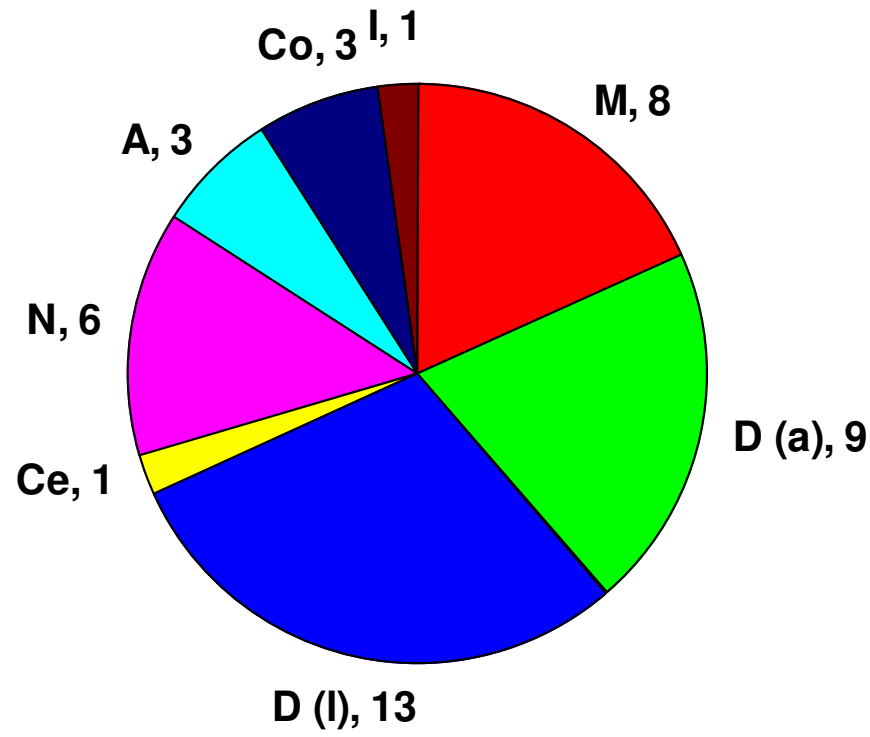

Black \& Azov seas

\section{Figure I}

Higher-level taxonomic structure of the macroparasite fauna of $L$. haematocheila in the Western North Pacific and the Black and Azov seas. Number of species per higher taxon indicated. Abbreviations: A, Acanthocephala; Ce, Cestoda; Co, Copepoda; D (a), Digenea (adult); D (I), Digenea (larval); I, Isopoda; M, Monogenea; N, Nematoda.

ing a substantial part of the species list in the introduced/ invasive range.

The data in Additional file 1 indicate that L. haematocheila has 'lost' 23 species of parasite ( 3 monogeneans, 13 digeneans, 1 cestode, 3 nematodes, 1 acanthocephalan, and 2 copepods) and 'gained' additional 34 species ( 1 monogenean, 22 digeneans, 1 cestode, 6 nematodes, 1 acanthocephalan, 2 copepods, and 1 isopod) following its introduction into the Sea of Azov and subsequent invasion of the Black Sea. Whereas problems with the identification may explain the small differences in the monogenean species lists (see below) there appears an apparent trend for replacement of the digenean fauna of L. haematocheila after its introduction in the Sea of Azov/ Black Sea. Thus, the waretrematine haploporids Platydidymus flecterotestis (Zhukov, 1971), Pseudohapladena mugili (Zhukov, 1971) and Skrjabinolecithum spasskii Belous, 1954 have been replaced in the new distributional range by the haploporine haploporids (Dicrogaster contracta Looss, 1902, Haploporus lateralis Looss, 1902, Haploporus sp., Saccocoelium obesum Looss, 1902 and Saccocoelium ten- sum Looss, 1902) and the haplosplanchnids Haplosplanchnus bivitellosus Zhukov, 1971, Hymenocotta mugilis Wang \& Wang, 1993 and Prohaplosplanchnus diorchis Tang \& Lin, 1978 by Haplosplanchnus pachysomus (Eysenhardt, 1829); the latter species groups being characteristic for mullets in the new areas. Furthermore, a large suite of larval forms (13 digenean and 4 nematode species) have been recorded mostly in the Sea of Azov. All these [with the exception of Hysterothylacium aduncum (Rudolphi, 1802) and Acanthostomum imbutiformis (Molin, 1859)] parasitise fish-eating birds (and some occasionally mammals) as adults. Unfortunately, the above picture is associated with a large number of non-documented records in the introduced/invasive range (i.e. lack of evidence for the identification of most adult and all larval digeneans, nematodes, acanthocephalans, copepods and isopods, see Additional file 1).

\section{Discussion}

The taxonomy of the genus Ligophorus has not been clarified in substantial detail due to the high morphological similarity of the species; a recently initiated dispute also 
concerns both species validity and distribution of the monogenean parasites of L. haematocheila. Sarabeev \& Balbuena [35] described Ligophorus pilengas Sarabeev \& Balbuena, 2004 from L. haematocheila in the Sea of Azov and Black Sea and provided a long list of synonyms of the new species: L. vanbenedeni (Parona \& Perugia, 1890) of Gusev [36]; L. chabaudi Euzet \& Suriano, 1977 of Dmitrieva [14], Maltsev \& Zhdamirov [19], Maltsev \& Miroshnichenko [23], Domnich \& Sarabeev [27,30,31], Sarabeev [33], and Sarabeev \& Domnich [34]. However, the material reported by Gusev [36] as L. vanbenedeni in L. haematocheila from Liao-Ho River (Yellow Sea basin) was considered a synonym of L. chabaudi by Euzet \& Suriano [37]. Miroshnichenko \& Maltsev [26] described L. gusevi Miroshnichenko \& Maltsev, 2004 from L. haematocheila in the Black Sea. Balbuena et al. [38] did not accept the distinct status of L. gusevi which they considered a junior synonym of L. pilengas Sarabeev \& Balbuena, 2004. Rubtsova et al. [39] considered the material reported as L. chabaudi by Dmitrieva [14], Sarabeev \& Balbuena [35] and Miroshnichenko \& Maltsev [26] synonymous with L. cephali Rubtsova et al., 2005 and concluded that L. chabaudi has not been found in the Black or Azov seas and that the record of this species in the East China Sea of Wu et al. [40] needs confirmation due to its zoogeographical incongruence. However, L. chabaudi of Dmitrieva [14] has been previously placed in synonymy with $L$. pilengas by Sarabeev \& Balbuena [35]; this controversy could be attributed to a nomenclatural error in the lists of synonyms in [35,39]. Sarabeev et al. [41] considered that Ligophorus mugilinus (Hargis, 1955) is restricted to the Western Atlantic and the Gulf of Mexico. Finally, Dmitrieva et al. [42] described a new species from $L$. haematocheila, $L$. llewellyni Dmitrieva, Gerasev \& Pron'kina, 2007 and assumed that the material described as L. pilengas may actually contain both species; these authors attributed the failure of Sarabeev \& Balbuena [35] to discriminate the two species to the insufficient number of measurements used by these authors. Clearly further effort is needed towards clarification of the taxonomic status and distribution of Ligophorus spp. in L. haematocheila.

The taxonomy of the haploporid digeneans in Additional file 1 is updated following the conclusions of the recent revision by Overstreet \& Curran [43]. Two of the three waretrematine haploporids originally described and subsequently reported only in mullets from the Western North Pacific $[44,45]$ were recombined by Overstreet \& Curran [43]. These authors found that Hapalotrema Zhukov, 1971 is preoccupied by Hapalotrema Looss, 1899 (a spirorchiid) and proposed Platydidymus Overstreet \& Curran, 2005 as the replacement name; Hapalotrema flecterotestis Zhukov, 1971 was thus recombined as Platydidymus flecterotestis (Zhukov, 1971) Overstreet \& Curran, 2005. Parasaccocoelium mugili Zhukov, 1971, the type- and only species of the genus Parasaccocoelium Zhukov, 1971, was placed by Overstreet \& Curran [43] in Pseudohapladena Yamaguti, 1952 as Pseudohapladena mugili (Zhukov, 1971) Overstreet \& Curran, 2005 thus making Parasaccocoelium a junior subjective synonym of Pseudohapladena. Dicrogaster contracta Looss, 1902 was considered a junior synonym of Dicrogaster perpusilla Looss, 1902 by Sarabeev \& Balbuena [46], a suggestion rejected by Blasco-Costa et al. [47] who redescribed the two species from newly collected Mediterranean material. The identification of $D$. contracta in the Black Sea/Azov Sea region is therefore questionable (Additional file 1).

The list of the records of the bunocotyline hemiurids in Additional file 1 follows the authors' original identification. However, the identification of all materials reported in L. haematocheila as Saturnius papernai Overstreet, 1977 requires confirmation. Domnich \& Sarabeev [28] described Bunocotyle constrictus Domnich \& Sarabeev, 1999 from Mugil soiuy in the Azov Sea, which they later (see e.g. $[29,32]$ ) considered a misidentification of $S$. papernai. However, Blasco-Costa et al. [47] re-examined the type- and voucher material of B. constrictus and revealed that all specimens were in poor condition, the egg-size measurements in the original description were erroneous etc. (see [47] for details). Due to these discrepancies, B. constrictus and its synonym (i.e. Saturnius papernai of Domnich \& Sarabeev inter alia) was considered a species inquirenda. Another doubtful record is of the bunocotyline hemiurid, Bunocotyle cingulata Odhner, 1928 in L. haematocheila in the Sea of Azov since it appears that a non-documented occurrence of a single worm in mullet fingerlings has been reiterated in a number of papers/ abstracts [27-30,32,34].

The systematics of the species of Diplostomum Nordmann, 1832 has long been controversial due to the phenotypic plasticity of the adult stage and the simple morphology of the larval stages. Identification of the metacercariae of Diplostomum spp. in particular, is practically impossible without experimental completion of the life-cycle due to the paucity of morphological features useful for larval identification and the specific requirements for specimen preparation and examination (see e.g. Shigin [48]; Niewiadomska \& Niewiadomska-Bugaj [49]). Furthermore, experimental studies have shown that the morphology of the metacercariae of D. paracaudum (Iles, 1959), D. pseudospathaceum Niewiadomska, 1984 and D. spathaceum (Rudolphi, 1819) can be affected by the host species, the density of infection, the size of the fish host, and the age of the metacercariae [50-53]. Any of these factors may generate differences between individuals of the same species in natural infections [49]. Therefore, although I have retained authors' identification of Diplostomum spp. metacercariae, the record of four species (i.e. D. spathaceum, D. 
paracaudum, D. rutili Razmashkin, 1969 and D. pseudospathaceum [reported as its synonym D. chromatophorum (Brown, 1931)] may depart from the real situation in the region and should be treated with caution (unfortunately all records are non-documented).

A comparison of the parasite faunas of L. haematocheila in its native and introduced/invasive range based on the records in the present checklist [14-45,47,54-77] demonstrates that a large number of parasite species was 'lost' in the new distributional range of the host whereas an even greater number was 'gained'. This results in the different higher-level taxonomic structure of the parasite faunas of this host in the two distributional areas and the small number of species (13\% of the total list, mostly monogeneans) in common between them. The stepwise introduction of L. haematocheila (1978 through 1984) attempted in the Azov Sea basin involved both fry and fish of different ages caught in the Amur and Ussuriisk bays of the Sea of Japan [78]. Therefore, the loss of parasites cannot be entirely attributed to introduced populations derived from uninfected life-history stages; this is supported by the records of most monogenean species (i.e. Gyrodactylus mugili, G. zhukovi, Ligophorus kaohsiangsieni, L. llewellyni and $L$. pilengas) transferred to the new distributional areas of the host $[14,22,35,42]$.

The replacement of the adult forms (notably the haploporid and haplosplanchnid digeneans) by 'alternative' species of the same families (and, therefore, utilising similar two-host life-cycle strategies with encystment of the cercariae on vegetation) can be considered a change related to the feeding habits of the host. This process appears to reflect biogeographical differences in the 'supply' since opportunities for transmission of the digenean species infecting L. haematocheila in the Western North Pacific probably do not exist in the new areas (e.g. the absence of the mollusc intermediate host). Further support to the 'supply-side' ecology of parasite transmission provides the 'gain' of the large suite of larval parasite stages (16 species utilising fish as second intermediate and fish-eating birds as definitive hosts). Although this may reflect both high bird and mullet abundance in the areas studied (Sivash, Molochnyi Liman and Obytochna Bay), all Ramsar wetlands of international importance supporting hundred thousands migrating and overwintering birds, I consider these records questionable since none is documented (see also the comment on larval Diplostomum spp. identification above).

\section{Conclusion}

Although the present checklist provides information that will facilitate future studies, the interesting question of macroparasite faunal diversity in L. haematocheila in its natural and introduced/invasive ranges cannot be dealt with the current data because of unreliability associated with the large number of non-documented and questionable records. This stresses the importance of data quality analysis in using host-parasite database and checklist data.

\section{Competing interests}

The author declares that they have no competing interests.

\section{Additional material}

\section{Additional file 1}

Checklist of macroparasites of Liza haematocheila. Checklist of helminth and crustacean parasites of Liza haematocheila with documented $\left({ }^{*}\right)$ and questionable (?) records marked. Abbreviations: MS, Mugil soiuy; $L H$, L. haematocheila.

Click here for file

[http://www.biomedcentral.com/content/supplementary/17563305-1-48-S1.doc]

\section{Acknowledgements}

I thank David Gibson and Rod Bray, The Natural History Museum, London, for their help with searching the Host-Parasite Database and two reviewers for their criticism and suggestions. This study was funded by Institute of Parasitology, Czech Academy of Sciences (grants Z602205I8 and LC522).

\section{References}

I. Parin NV: An annotated catalogue of fish-like vertebrates and fishes of the seas of Russia and adjacent countries: Part 3. Orders Perciformes (excluding suborders Gobioidei, Zoarcoidei and Stichaeoidei) and Tetraodontiformes. Voprosy Ikhtiologii 2003, 43(SuppI I):SI-S40.

2. Fricke R, Bilecenoglu M, Musa Sari H: Annotated checklist of fish and lamprey species (Gnathostomata and Petromyzontomorphi) of Turkey, including a Red List of threatened and declining species. Stuttgarter Beiträge zur Naturkunde. Ser A (Biologie) 2007, 706: I-174.

3. Eschmeyer WN: Catalog of Fishes electronic version (updated 23 April 2008). [http://www.calacademy.org/research/ichthyology/ catalog/fishcatsearch.html].

4. Occhipinti-Ambrogi A, Savini D: Biological invasions as a component of global change in stressed marine ecosystems. Mar Poll Bull 2003, 46:542-551.

5. Kottelat M, Freyhof J: Handbook of European freshwater fishes Cornol, Switzerland: Publications Kottelat; 2007.

6. Okumus I, Bascinar N: Population structure, growth and reproduction of introduced pacific mullet, Mugil soiuy, in the Black Sea. Fisheries Research 1997, 33:131-137.

7. Starushenko LI, Kazanski AB: Introduction of mullet haarder (Mugil so-iuy Basilewsky) into the Black Sea and the Sea of Azov. General Fisheries Council for the Mediterranean. Studies and Reviews 1996, 67:1-29.

8. Dogiel VA: Ecology of the parasites of freshwater fish. In Parasitology of Fishes (English Translation) Edited by: Dogiel VA, Petrushevski GK, Polyanski Yul. Edinburgh: Oliver \& Boyd; 1961: I-47.

9. Dogiel VA: General Parasitology (English translation) Edinburgh: Oliver \& Boyd; 1964.

10. Kennedy C, Bush AO: The relationship between pattern and scale in parasite communities: a stranger in a strange land. Parasitology 1994, 109:187-196.

II. Torchin ME, Lafferty KD, Kuris AM: Parasites and marine invasions. Parasitology 2002, I 24(Suppl):SI37-I5I.

12. Torchin ME, Lafferty K, Dobson A, McKenzie VJ, Kuris AM: Introduced species and their missing parasites. Nature 2003, $421: 628-629$ 
13. Gibson DI, Bray RA, Harris EA, (Compilers): Host-Parasite Database of the Natural History Museum, London (Updated 2005). [http://www.nhm.ac.uk/research-curation/projects/host-parasites/]

14. Dmitrieva EV: Fauna of Monogenea of the Far East Mugil soiuy in the Black Sea. Vestnik Zoologii 1996, 5-6:95-97.

15. Gaevskaya AV, Dmitrieva EV: Overview of Black Sea monogenean fauna. Ekologiya Morya 1997, 46:7-16.

16. Gaevskaya AV, Dmitrieva EV: Monogenean fauna from the Black Sea: current overview [abstract]. In Programme and Abstracts of the 3rd International Symposium on Monogenea: 25-30 August 1997; Brno, Czech Republic Edited by: Gelnar M. Czech Parasitological Society; 1997:28.

17. Dmitrieva E: The monogeneans of the Black Sea (Updated 1998). [http://www.ibss.iuf.net].

18. Dmitrieva EV, Gaevskaya AV: Parasitological aspects of mugilids mariculture and of their introduction into the Sea of Azov and the Black Sea. Ekologiya Moriya 200I, 55:73-78.

19. Maltsev VN, Zhdamirov VN: Parasitofauna of the haarder (Mugil soiuy Basilewsky) of the Kerch Channel. Proceedings of the Southern Scientific Research Institute of Marine Fisheries and Oceanography 1996, 44:229-232.

20. Maltsev VN: Some parasitological aspects of the introduction of Mugil soiuy Basilewski in the Azov-Black Sea basin [abstract]. Biomonitoring and sustainable use of hydrobionts. Young scientists conference: 27-29 May 1997; Vladivostok 1997:49-50.

21. Miroshnichenko Al, Maltsev VN: Monogeneans of Pacific haarder, Mugil soiuy, in the Azov Sea [abstract]. In Programme and Abstracts of the 3rd International Symposium on Monogenea: 25-30 August 1997; Brno, Czech Republic Edited by: Gelnar M. Czech Parasitological Society; 1997:73.

22. Maltsev V, Miroshnichenko A: On transcontinental transfer of parasites from the Far East into the Black and Azov Seas in the process of haarder (Mugil soiuy) acclimatization [ICOPA IX abstract]. Parasitology International 1998, 47(Suppl):325.

23. Maltsev VN, Miroshnichenko Al: Peculiarities of monogenean infestation of Pacific haarder in the Azov Sea [abstract]. In Problems in flatworm systematics and phylogeny Saint Petersburg: Institute of Zoology of the Russian Academy of Sciences; 1998:66-67.

24. Miroshnichenko Al, Maltsev VN: Species of Gyrodactylus (Monogenea, Gyrodactylidae) from Soiuy mullet new for the AzovBlack Sea basin. Proceedings of the Southern Research Institute of Marine Fisheries and Oceanography 1998, 44: I I6-I 25.

25. Maltsev VN, Zhdamirov VN: Parasite infestation and ichthyopathological state of commercial fishes in Azov Sea [abstract]. Pontus Euxinus 2000. Young scientists conference: 16-18 May 2000; Sevastopol 2000:4I-42.

26. Miroshnichenko Al, Maltsev VN: Ligophorus gussevi sp. nov. (Monogenea: Ancyrocephalidae) - a new species of gill parasite of So-iuy mullet (Mugil soiuy). In Notes on the development of the Crimea. Collection of analytical, scientific and practical articles open to discussion. Is. 15. Problems of the ecology in the Crimea. Inventory of animals and plants in the Crimea Edited by: Dulitskiy AN et al. Simferopol: Tavriya-Plus; 2004:186-192.

27. Domnich IF, Sarabeev VL: Formation of the parasite fauna of Mugil soiuy in the Azov Sea. Visnik Zaporiz'kogo Derzhavnogo Universitetu 1999, 2:218-223.

28. Domnich IF, Sarabeev VL: Trematodes of the genus Bunocotyle (Trematoda, Halipegidae) from the haarder (Mugil so-iuy) acclimatized in the Azov Sea. Parazitologiya 1999, 33:67-70.

29. Domnich IF, Sarabeev VL: Contemporary fauna of fish parasites in the northern part of the Azov Sea. Visnik Zaporiz'kogo Derzhavnogo Universitetu 2000, I:224-230.

30. Domnich IF, Sarabeev VL: Forming of the parasitic fauna of the pilengas in the Asov Sea [abstract]. Acta Parasitologica 2000, 45:265-266.

31. Domnich IF, Sarabeev VL: Parasitic fauna structure of the pilengas in the Azov Sea [abstract]. Acta Parasitologica 2000, 45:268.

32. Domnich IF, Sarabeev VL: The trematodes of the Far-East-mullet-pelingas (Mugil soiuy) in the Azov Sea aquatories. Vestnik Zoologii 2000, 34:7-I5.

33. Sarabeev V: Seasonal dynamics of the parasitic infection of the pilengas in the northern part of the Azov Sea [abstract]. Materials of the international scientific conference of young scientists 'Aquatic biological resources and ways of their rational use'; Kiev 2000:97-98.
34. Sarabeev VL, Domnich IF: Age-related dynamics of parasitic infection of the pilengas (Mugil soiuy) in the Molochny Estuary of the Sea of Azov. Vestnik Zoologii 2000, I4:6-I2.

35. Sarabeev VL, Balbuena JA: Ligophorus pilengas n. sp. (Monogenea: Ancyrocephalidae) from the introduced So-iuy mullet, Mugil soiuy (Teleostei: Mugilidae), in the Sea of Azov and the Black Sea. J Parasitol 2004, 90:222-228.

36. Gusev AV: Order Dactylogyridea. In Keys to the parasites of freshwater fish of the USSR fauna. Metazoan parasites Volume 2. Edited by: Gusev AV, Dubinina MN, Pugachev ON, Raykova EV, Hotenovskiy IA, Ergens R. Leningrad: Nauka; 1985: I5-25.

37. Euzet L, Suriano DM: Ligophorus n. g. (Monogenea, Ancyrocephalidae) parasite des Mugilidae (Téléostéens) en Méditerranée. Bulletin du Muséum National d'Histoire Naturelle, 3e Sér. Zoologie 1977, 472:799-822.

38. Balbuena JA, Rubtsova NY, Sarabeev VL: Ligophorus pilengas Sarabeev \& Balbuena, 2004 (Monogenea: Ancyrocephalidae) is proposed as the senior synonym of $L$. gussevi Miroshnichenko \& Maltsev, 2004. Syst Parasitol 2006, 63:95-98.

39. Rubtsova NY, Balbuena JA, Sarabeev VL, Blasco-Costa I, Euzet L: Description and morphometrical variability of a new species of Ligophorus and of Ligophorus chabaudi (Monogenea: Dactylogyridae) on Mugil cephalus (Teleostei) from the Mediterranean basin. J Parasitol 2006, 92:486-495.

40. Wu B-h, Sun X-d, Song C-c, (Editors): Fauna of Zhejiang. Trematoda Zhejiang: Zhejiang Science and Technology Publishing House; 199I.

4I. Sarabeev VL, Balbuena JA, Euzet L: Taxonomic status of Ligophorus mugilinus (Hargis, 1955) (Monogenea: Ancyrocephalidae), with a description of a new species of Ligophorus from Mugil cephalus (Teleostei: Mugilidae) in the Mediterranean basin. J Parasitol 2005, 9 I: |444-|45|.

42. Dmitrieva EV, Gerasev PI, Pron'kina NV: Ligophorus llewellyni n. sp. (Monogenea: Ancyrocephalidae) from the redlip mullet Liza haematocheilus (Temminck \& Schlegel) introduced into the Black Sea from the Far East. Syst Parasitol 2007, 67:5 I-64.

43. Overstreet RM, Curran SS: Family Haploporidae Nicoll, I 9 I 4. In Keys to the Trematoda Volume 2. Edited by: Jones A, Bray RA, Gibson DI. Wallingford: CAB International; 2005: I29-165.

44. Belous EV: On the systematics of the family Haploporidae Nicoll, 19|4. Trudy GELAN 1954, 7:277-28I.

45. Zhukov EV: New trematodes of marine and freshwater fishes from the basins of the Japan and Yellow Seas. Parazitologiya 197|, 5:|55-161.

46. Sarabeev VL, Balbuena JA: Morphological variability of Dicrogaster contracta Looss, 1902 (Digenea: Haploporidae) and its proposed synonymy with $D$. perpusilla Looss, 1902. Syst Parasitol 2003, 55:25-3l.

47. Blasco-Costa I, Montero FE, Gibson DI, Balbuena JA, Raga JA, Shvetsova LS, Kostadinova A: A revision of the species of Saturnius Manter, 1969 (Digenea: Hemiuridae), parasites of mullets (Teleostei: Mugilidae). Syst Parasitol 2008, 7 I:53-74.

48. Shigin AA: The trematode fauna of the USSR. Genus Diplostomum. Metacercariae Moscow: Nauka; 1986.

49. Niewiadomska K, Niewiadomska-Bugaj M: Optimal identification procedure for Diplostomum paracaudum (Iles, 1959) and D. pseudospathaceum Niewiadomska, 1984 metacercariae (Digenea) based on morphological characters. Syst Parasitol 1995, 30:165-171.

50. Niewiadomska K, Szymafiski S: Host-induced variability of Diplostomum paracaudum (Iles, 1959) metacercariae (Digenea). Acta Parasitol Polon 1991, 36: I I-17.

5I. Niewiadomska K, Szymafiski S: Host-induced variability of Diplostomum pseudospathaceum Niewiadomska, 1984 metacercariae (Digenea). Acta Parasitol 1992, 37: I I-I7.

52. Graczyk TL: Variability of metacercariae of Diplostomum spathaceum (Rudolphi, I819) (Trematoda, Diplostomidae). Acta Parasitol Polon 1991, 36:135-139.

53. Graczyk T: Variability of metacercariae of Diplostomum pseudospathaceum Niewiadomska, 1984 (Trematoda, Diplostomidae). Acta Parasitol 1992, 37:5-9.

54. Wu B, Long S, Wang W, et al.: Fauna Sinica. Platyhelminthes. Monogenea Beijing: Science Press; 2000.

55. Nizova GA, Kovtun IF, Syrovatka NI: Peculiarities of the formation and epizootic importance of the parasite fauna of Soiuy mullet acclimated in the water bodies of the Azov basin 
[abstract]. Vosmoi S'ezd Gidrobiologicheskogo Obshchtestva 200I, 2:13-14.

56. Gaevskaya AV, Korniychuk YM: Parasitic organisms as a component of ecosystems of the Black Sea near-shore zone of Crimea. In Modern condition of biological diversity in near-shore zone of Crimea (Black Sea sector) Edited by: Eremeev VN, Gaevskaya AV. Sevastopol: EKOSI-Gidrophizika; 2003:425-490.

57. Zhang J-y, Yang T-b, Liu L, Ding X-j: A list of monogeneans from Chinese marine fishes. Syst Parasitol 2003, 54: I II-I 30.

58. Ji G-I, Zhang C-y, Chen C-f: A list monogenetic trematodes of freshwater fishes from China. J Huazhong Agricult Coll 1982, 4:1-32.

59. Pan J-h, Zhang J-y, Li Z-c: Parasitology of fishes: A survey of study of parasites appearing in Chinese freshwater fishes 1990.

60. Zhukov EV: New species of trematodes and monogeneans of marine fish of Possjet Bay (Sea of Japan). Parazitologiya 1970, 4:32I-326.

61. Paperna I, Overstreet RM: Parasites and diseases of mullets (Mugilidae). In Aquaculture of Grey Mullets Edited by: Oren $\mathrm{OH}$. Cambridge: Cambridge University Press; 1981:4 I I-493.

62. Ling M-n: Notes on seven new parasitic species from monogenetic trematodes - Gyrodactylus from fresh-water fishes of China. Acta Hydrobiologica Sinica 1962, I 2:67-78.

63. Zabodash VM, Semenenko LI: Parasite fauna of Mugil soiuy in water bodies of Ukraine. Vestnik Zoologii 1994, 2:44-46.

64. Shen J-w, Qiu Z-z: Studies on the trematodes of fishes from the Yellow Sea and Bo Hai Sea Beijing: Science Press; 1995.

65. Huang Z-g: Marine species and their distribution in China's Seas Malabar, Florida: Krieger Publishing Company; 200I.

66. Li M-m: Parasites of the mullets Mugil cephalus (Linnaeus) and Liza haematocheila (Temminck et Echlegel) in the areas of Bohai Gulf, Hangu Area. Acta Zool Sinica 1984, 30:153-158.

67. Li Q-k, Qiu Z-z, Zhang R-s: Digenetic trematodes of fishes from the Bo-hai Sea, China VI (Trematoda: Opecoelidae). Acta Zootaxon Sinica 1989, 14:12-16.

68. Korniychuk JM: First record of trematodes from the haarder, Mugil soiuy Basilewsky (Pisces: Mugilidae) in the Black Sea. Ecologiya Morya 200I, 59:2I-22.

69. Wang P-q, Wang Y-y: Some digenetic trematodes of marine fishes from Fujian Province. J Fujian Normal Univ (Nat Sci) 1993, 9:66-73.

70. Tang $Z$, Lin $X:$ Three new species and one new genus of trematodes belonging to the family Haplosplanchnidae Poche, 1925. Acta Zool Sinica 1978, 24:203-2II.

71. Zhdamirov VN, Maltsev VN: The trematode genus Saturnius Manter, 1969 (Trematoda, Bunocotylidae) - parasites of mullets in the Azov-Black Basin. Problems of icthyopathology. Materials of the First All-Ukranian Conference: 23-26 October, 200I 200I:I-4.

72. Shen J-w: Description of four new species (Lepocreadiidae and Hemiuridae) and a list of digenetic trematodes of fishes from Yellow Sea. Marine Sci Bull 1990, 9:54-63.

73. WHO study group report: Control of foodborne trematode infections. WHO Technical Report Series 1995:849.

74. Chung P-r, Sohn W-m, Jung Y, Pai S-h, Nam M: Five human cases of Diphyllobothrium latum infection acquired through eating raw flesh of redlip mullet, Liza haematocheila. Korean J Parasitol 1997, 35:283-289.

75. Podushka SB, Galkin AK: Ligulosis in young of the year pilengas in Azov Sea. Nauchno-Tekhnicheckiy Byuletin Laboratorii Ikhtiologii INEKO 2000, 4:4-7.

76. Belous EV: On the systematics of the family Haploporidae Nicoll, 1914. Trudy GELAN 1954, 7:277-281.

77. Yin W-y, Wu H-s: The parasitic Acanthocephala of fishes from Liao He in China. In Parasitic organisms of freshwater fish of China (Compiled and edited by Institute of Hydrobiology Academia Sinica) Beijing: Agricultural Publishing House; 1984:200-215.

78. Kizer Al: Mullet in the Sea of Azov. Netraditsionnye ob"ekty vyrashchivaniya i problemy akklimatizatsii (Inform. paket VNIERKh) (Unusual Subjects of Rearing and Problems of Acclimation (Information Package of the Institute of Ecology and Fishery) 1991: 10-II.
Publish with Bio Med Central and every scientist can read your work free of charge

"BioMed Central will be the most significant development for disseminating the results of biomedical research in our lifetime. "

Sir Paul Nurse, Cancer Research UK

Your research papers will be:

- available free of charge to the entire biomedical community

- peer reviewed and published immediately upon acceptance

- cited in PubMed and archived on PubMed Central

- yours - you keep the copyright

Submit your manuscript here:

http://www.biomedcentral.com/info/publishing_adv.asp
BioMedcentral 